\title{
Medication review, polypharmacy and deprescribing: Results of a pilot scoping exercise in undergraduate and postgraduate education
}

\author{
Nina Barnett1,2 iD, Barry Jubraj1 iD, Daniel Grant³ iD , Bhavana Reddy ${ }^{4}$, Jennifer M Stevenson 5,6 iD \\ 1 NHS Specialist Pharmacy Service, United Kingdom \\ 2 Kingston University London, United Kingdom \\ ${ }^{3}$ School of Pharmacy, University of Reading, United Kingdom \\ ${ }^{4} \mathrm{NHS}$ England and NHS Improvement, United Kingdom \\ ${ }^{5}$ Guy's and St. Thomas' NHS Foundation Trust, United Kingdom \\ ${ }^{6}$ Institute of Pharmaceutical Science, King's College London, United Kingdom
}

\author{
Keywords \\ Deprescribing \\ Inappropriate prescribing \\ Medical education \\ Medication review \\ Pharmacy education \\ Polypharmacy \\ Undergraduate education

\section{Correspondence} \\ Nina Lee Barnett \\ Pharmacy Department \\ Northwick Park Hospital \\ Watford Road \\ Harrow HA1 3UJ \\ nina.barnett@nhs.net
}

\begin{abstract}
Background: As part of tackling polypharmacy, effective medication review and safe deprescribing are key to World Health Organisation's (WHO) 3rd Global Patient Safety Challenge. There is little information about whether this occurs consistently in pharmacy and medicine courses in England. Objective: To create a snapshot of medication review, polypharmacy and deprescribing educational activity in a small number of university courses for medicines, pharmacy and non-medical prescribing. Method: The authors undertook a pilot scoping exercise by emailing colleagues in schools of pharmacy and medicine across England about course inclusion of medication review and deprescribing. 11 universities, describing 17 programmes, responded (eight undergraduate pharmacy, four undergraduate medicine, four postgraduate medicine, one non-medical prescribing course). Data were categorised as: programme content, tools to support deprescribing, learning outcomes, and future intentions for deprescribing teaching. Results: The results suggested variation in what was being taught. Conclusion: In order to address both national and international agenda, the authors suggest that inclusion of training in this area and consistency of curricula are crucial to adequately equipping our future workforce to be fit for purpose.
\end{abstract}

\section{Introduction}

The World Health Organisation's (WHO) 3rd Global Patient Safety Challenge seeks to tackle the issues of polypharmacy, high-risk medicines and transitions of care (World Health Organisation, 2017). The National Institute for Health Research (NIHR) Collaboration for Leadership in Applied Health Research and Care (CLAHRC) Northwest London (NWL) had an active medicines optimisation work stream which included improving safety in medicine prescribing and use through medication review. Undertaking a medication review may include a number of actions, including deprescribing to reduce the risks of medicines-related harm (MRH). Therefore, it is important that the concept of medication review is introduced to undergraduate and novice practitioners (hereafter referred to as 'juniors'). Examples of these include the 'deprescribing medicines' online module that has been developed in Australia (Gowan, 2018).

Determining the appropriateness and safety of medication through medication review requires careful consideration of the risks versus benefits of particular medicines for individual patients. There are a number of factors associated with medicines-related harm and while risk prediction models to identify those most at risk have been developed, their limited predictive ability precludes their 
uptake into clinical practice (Stevenson, 2014). Clinical tools are available to support medication review, for example the validated, evidence-based STOPP/START tool (O'Mahoney et al., 2015). This was adapted for local use in north west London as the 'STOPIT' tool (Saheb et al., 2014) to encourage all pharmacists, nurses and doctors to contribute to the medication review agenda. The practice of regular medication review using a patient-focused approach has been promoted by the Choosing Wisely campaign (Academy of Medical Royal Colleges, 2019). This encourages patients to think about what matters to them in relation to benefits and harms of treatments, including potential alternatives or no treatment, at the time of the consultation, recognising that things may change. The clinician can then use their clinical judgement and expertise, combined with the best research evidence and knowledge of the patient perspective (Sackett et al., 1996) in co-creating a treatment plan with the patient. This may ultimately reduce the number of medicines prescribed, and so reduce the risk of $\mathrm{MRH}$; this is the essence of deprescribing.

Whilst the concept of medication review is generally accepted, the concept of deprescribing and the use of the term itself are relatively new. Deprescribing is not the simple practice of stopping medicines, rather, it is the complex process required for the safe and effective cessation (withdrawal) of inappropriate medication which takes into account the patient's physical functioning, comorbidities, preferences and lifestyle' (Drug and Therapeutics Bulletin, 2014). Stopping medicines may or may not be the appropriate response to polypharmacy; however, even when appropriate, there are barriers to deprescribing, which include the patient understanding of the term itself (Anderson et al., 2014; Reeve, Low, \& Hilmer, 2016). It is important to ensure that juniors are introduced to these concepts and challenges in a way that is appropriate for their level of professional development that equips them to engage with the prevention of $\mathrm{MRH}$ in collaboration with their seniors and colleagues.

Scott and colleagues have alluded to the need for appropriate curricula in universities regarding drug use and integrating deprescribing (Scott et al., 2015). In 2014, as part of a medicines optimisation work stream, NIHR CLAHRC NWL considered the educational imperatives around polypharmacy, medication review and deprescribing, leading to a pilot survey of junior doctors' views and perceptions of roles and responsibilities (Jubraj et al., 2015). Subsequent surveys of medical, pharmacy and nursing students were conducted to elucidate and compare awareness of these concepts and students' views, particularly around roles and responsibilities. NIHR CLAHRC NWL also engaged with universities and other institutions to suggest the inclusion of relevant learning outcomes and teaching (Poots, Jubraj \& Barnett, 2017) through application of what was described as 'the bottomup approach to education around medication review and deprescribing'. This is based upon the theory that appropriate teaching is needed in their early years in order to equip juniors to actively participate in the medication review agenda in the future (Jubraj et al., 2015). This can include learning how to find out what is important to the patient using a variety of available tools (NHS Scotland and the Scottish Government, 2018; Academy of Medical Royal Colleges, 2019; Institute for Healthcare Improvement, 2019; Royal Pharmaceutical Society, 2019).

In 2020/2021 there were 42 medical schools and 32 universities which offered a pharmacy degree in the United Kingdom (UK) (General Pharmaceutical Council, 2020). There is a paucity of literature exploring existing education around these concepts, alongside a national imperative to manage problematic polypharmacy (Duerden, Avery, \& Payne, 2013) and a recognised need to support safe deprescribing (Department of Health and Social Care, 2018). This paper outlines a pilot scoping exercise, undertaken in the autumn of 2018 , that aimed to identify existing teaching in this area and make recommendations for learning outcomes in order to meet the relevant WHO priority of tackling polypharmacy.

\section{Methods}

17 personal contacts and colleagues in schools of pharmacy and medicine across Great Britain were contacted by email in June 2018 to request information about and examples of relevant teaching by the authors. The outline of the project was provided, and any teaching material covering medication review and deprescribing, relevant learning outcomes, and consent to anonymously include their responses and publish the overall findings were requested. An analysis proforma was designed by the co-authors (see Appendix 1 ) which included requests for information on topics covered, tools used, aim of the work and identified gaps in key topics (Polypharmacy, medication review, deprescribing). All key topics are part of medicines optimisation identified by authors as relevant to this area of work. Responses were analysed against the analysis proforma and responses presented descriptively. 


\section{Results}

Information relating to all 17 programmes, from 11 Universities contacted, was received from across England including eight undergraduate pharmacy (M.Pharm.) programmes, four undergraduate medicine (MBBS) programmes, four postgraduate pharmacy programmes and one postgraduate non-medical prescribing programme. Analysis of the data was undertaken in four categories: programme content, tools to support deprescribing, learning outcomes, and future intentions in relation to deprescribing teaching.

\section{Programme content}

Variation was found in programme content, with 'polypharmacy' being the most common topic explicitly addressed (in 12 programmes) and 'medication review' and 'medicines optimisation' being covered to a lesser extent. Coverage of the four topics is shown in Table I.

Table I. Number of programmes addressing the four topic areas being investigated (UG - undergraduate, PG postgraduate)

\begin{tabular}{lllll}
\hline $\begin{array}{l}\text { Programme } \\
\text { type }\end{array}$ & Polypharmacy & $\begin{array}{l}\text { Medication } \\
\text { review }\end{array}$ & Deprescribing & $\begin{array}{l}\text { Medicines* } \\
\text { Optimisation }\end{array}$ \\
\hline $\begin{array}{l}\text { UG Pharmacy } \\
(n=8)\end{array}$ & $6(75.0 \%)$ & $6(75.0 \%)$ & $6(75.0 \%)$ & $5(62.5 \%)$ \\
$\begin{array}{l}\text { PG Pharmacy } \\
(n=5)\end{array}$ & $3(60.0 \%)$ & $2(40.0 \%)$ & $3(60.0 \%)$ & $2(40.0 \%)$ \\
$\begin{array}{l}\text { UG Medicine } \\
(n=4)\end{array}$ & $3(75.0 \%)$ & $0(0.0 \%)$ & $1(25.0 \%)$ & $1(25.0 \%)$ \\
Total $(n=17)$ & $12(70.6 \%)$ & $8(47.0 \%)$ & $10(58.9 \%)$ & $8(47.0 \%)$ \\
\hline
\end{tabular}

*Medicines optimisation was not directly identified in the proforma, but was drawn from free text responses

Polypharmacy had similar levels of coverage across the different types of programmes, whereas the other three topic areas were more varied, being particularly poorly covered in the undergraduate medicine programmes. The care of older people was the context for teaching these topics in seven programmes, although there was a lack of detail provided for this aspect in several responses.

\section{Learning outcomes}

Variation was noted in the use of learning outcomes relating to the topics being investigated, as shown in Table II.

Several programmes introduced medication review, polypharmacy and deprescribing tools (Saheb et al., 2014;
All Wales Medicines Strategy Group, 2014; Boustani, et al., 2008; Consultant Pharmacy Services, 2016; Cumbria, 2013; Fick, et al., 2015; Lewis, 2005; NICE, 2016; Royal Pharmaceutical Society, 2014; Scottish Government Polypharmacy Model of Care Group, 2018) to students as part of their teaching of the topics investigated.

\section{Future intentions}

When considering future improvements, more explicit coverage of deprescribing was the most common intended change (seven programmes). Approaches to change varied from introduction of more specific learning outcomes regarding deprescribing, to the use of objective, structured, clinical examinations (OSCES) and presentations to address concepts relating to the subject. For the postgraduate prescribing programme, it was noted that primary care prescribers would like to learn more about deprescribing but feel constrained by guidance for long term conditions, and that prescribing targets and associated payments are also barriers.

Table II. Use of learning outcomes relating to polypharmacy, medication review, deprescribing and medicines optimisation of

\begin{tabular}{|c|c|c|}
\hline Topic & $\begin{array}{l}\text { programmes } \\
\text { with specific } \\
\text { I e a r n i n g } \\
\text { outcomes ( } \\
=17 \text { ) }\end{array}$ & Example learning outcomes \\
\hline Polypharmacy & 3 & $\begin{array}{l}\text { Critically evaluate and demonstrate } \\
\text { how medicines review tools can be } \\
\text { used to deprescribe in patients } \\
\text { with inappropriate polypharmacy }\end{array}$ \\
\hline $\begin{array}{l}\text { Medication } \\
\text { review }\end{array}$ & 5 & $\begin{array}{l}\text { Discuss polypharmacy and } \\
\text { medication review }\end{array}$ \\
\hline & & $\begin{array}{l}\text { Describe the key principles of } \\
\text { deprescribing }\end{array}$ \\
\hline Deprescribing & 5 & $\begin{array}{l}\text { Use the STOPIT tool to apply your } \\
\text { understanding of the principles of } \\
\text { deprescribing }\end{array}$ \\
\hline $\begin{array}{l}\text { M e d i c i n e s } \\
\text { optimisation }\end{array}$ & 1 & $\begin{array}{l}\text { Make recommendations to } \\
\text { optimise medication for older } \\
\text { people in simulated case scenarios }\end{array}$ \\
\hline
\end{tabular}

\section{Discussion}

This pilot scoping exercise was undertaken with the aim of providing an initial snapshot of educational activity in the priority areas of medication review, polypharmacy and deprescribing in a selection of higher education programmes, particularly within pharmacy in England. Although the sample size was small and a convenience sample used, these results suggest that there is variation 
in what is being taught. In order to address both national and international agendas around medicines optimisation and safety, the authors believe that inclusion of training in this area and consistency of curricula are crucial to adequately equipping our future workforce to be fit for purpose. Strategic recommendations from Health Education England and professional regulators may improve and appropriately standardise the key messages that juniors need to grasp in order to effectively contribute to the medicines optimisation agenda.

\section{Programme content and learning outcomes}

Polypharmacy was the most common teaching topic compared with medication review, deprescribing and medicines optimisation. The authors found no mention of polypharmacy in one-third of the programmes surveyed, although it is recognised that teaching may exist elsewhere. Given the importance of medication review in tackling inappropriate polypharmacy, a wider coverage of this topic would be expected, particularly in postgraduate pharmacy programmes where juniors are gaining practical experience of medicines use. The results suggest that there is scope to develop learning outcomes that address the national agenda on medication review, polypharmacy and deprescribing as in this cohort, only one-third of programmes contained these topics. In the example learning outcomes contained in Table II, none related to shared decision-making, which is a central element of a medication review (National Institute for Health and Care Excellence, 2015). The authors' experience of writing learning outcomes on these topics has been positive in our efforts to translate national priorities and National Health Service (NHS) policy (NHS England, 2019) which provide a mandate for this work, into meaningful educational strategies to prepare juniors for practice.

\section{Medication review tools}

The results suggest that some juniors are introduced to medication review tools which may be helpful in identifying potentially inappropriate medicines. Such tools can be useful in introducing juniors to these medicines, to identify risks with key medicines, such as analgesics and antihypertensives and to identify patients with high anticholinergic burden. Familiarity with tools to support medicines optimisation through reducing inappropriate polypharmacy and MRH will support clinicians throughout their careers to identify opportunities for undertaking medication review and increase their confidence to do so.

\section{Opportunities to develop education of juniors}

The intention of a number of programmes to expand coverage of concepts such as deprescribing is to be welcomed. Introduction of assessments such as OSCEs in this area, underpinned by appropriate education and associated learning outcomes, will help to embed bbjective structured clinical examination as part of everyday activity.

In order to optimise medicines for patients with multimorbidity and encourage practitioners to consider more than just guideline-based recommendations, the focus in education needs to move away from a single disease guideline-based treatment model. Juniors can be upskilled to recognise where a paucity of evidence leads to clinical uncertainty, how to use appropriate guidelines to support decision making in this situation (National Institute for Health and Care Excellence, 2016), and how to include patient values in decision making, using valuesbased practice (Fulford, 2011). Moreover, the importance of psychological and social influences on how medicines are used and the impact on an individual's health beliefs on adherence and the risk of harm from medicines need to be addressed. Development of knowledge and skills in these areas will support the delivery of a comprehensive medication review. Through prompting their seniors to undertake a medication review, juniors will be able gain experience and readiness to initiate medication reviews as seniors (Jubraj et al., 2015). The CLAHRC NWL 'bottom-up approach to education around medication review and deprescribing' has provided a local framework for engaging universities in promoting the need for appropriate education (Jubraj et al., 2015).

As the concept of deprescribing is introduced to juniors, it is important that it is firmly embedded within the process of medication review. It should form part of a comprehensive assessment, especially in frail older adults, with involvement from all relevant members of the multidisciplinary team. Inter-professional education, particularly at undergraduate level, may help juniors to understand the need for multidisciplinary collaboration when reviewing medicines. The 'Silver Book' (Conroy, 2021), whilst focussing on the urgent care needs of older adults, makes recommendations that are more widely applicable in healthcare. These aid and support the further extension of such multidisciplinary training to include those in health care agencies, social services and community teams, a group of professionals frequently involved in medicines use in older adults. This holistic 
approach to supporting reduction of inappropriate polypharmacy through medication review and deprescribing will encourage juniors to associate starting a medicine with asking themselves the question, 'when will this be reviewed and/or stopped?'.

\section{Limitations}

This scoping exercise is limited because of the small sample size and informal approach (convenience sample) to known contacts of the authors to gather information about educational provision, which limit generalisability of the results. However, this work makes an early contribution to the discussion about the need for specific learning outcomes, appropriate teaching and some form of assurance that all juniors will be introduced to these important concepts early in their career.

\section{Recommendations}

1.For stakeholders such as NHS England and Health Education England to collaborate with professional regulators and educational institutions to ensure that these important medicines-related imperatives are taught in appropriate curricula, with periodic joint review as practice and policy evolves

2.For these stakeholders to make broad recommendations for appropriate learning outcomes and content that reflect the challenges of current practice. A standard approach could increase the confidence of healthcare professionals in stopping medicines

3.For all healthcare professionals to be trained in shared decision-making, enabling them to utilise their learning (including medication review tools) and have appropriate conversations about deprescribing with patients

\section{Conclusion}

The national and international imperatives to improve safe use of medicines include management of problematic polypharmacy though medication review, which can include deprescribing. If taught at undergraduate and novice practitioner level these activities can be embedded in everyday practice across professional boundaries. This work suggests that there are opportunities for improvement in the content and coverage of these concepts to develop curricula. Collaboration between NHS national bodies and professional regulators to recommend inclusion of these subjects as part of health professional training would promote improved skills in this area for novice practitioners.

Disclaimer: This research was supported by the National Institute for Health Research (NIHR) Collaboration for Leadership in Applied Health Research and Care Northwest London (NIHR CLAHRC NWL). The views expressed in this article are those of the author(s) and not necessarily those of the NHS, the NIHR, or the Department of Health and Social Care.

\section{References}

Academy of Medical Royal Colleges. Choosing Wisely principles (online). Available from: https://www.choosingwisely.co.uk/ about-choosing-wisely-uk/

All Wales Medicines Strategy Group. (2014) Polypharmacy: Guidance for Prescribing (online). Available from: https:// awmsg.nhs.wales/medicines-appraisals-and-guidance/ medicines-optimisation/prescribing-guidance/polypharmacyguidance-for-prescribing/

Anderson, K., Stowasser, D., Freeman, C., \& Scott, I. (2014) Prescriber barriers and enablers to minimising potentially inappropriate medications in adults: a systematic review and thematic synthesis. BMJ Open, 4(12), https://bmjopen.bmj.com/ content/4/12/e006544

Boustani, M., Campbell, N., Munger, S., Maidment, I., \& Fox, C. (2008). Impact of anticholinergics on the aging brain: a review and practical application.

Conroy, S. (2021) Quality Care for Older people with Urgent and Emergency Care needs (online). Available from: https:// www.bgs.org.uk/resources/resource-series/silver-book-ii

Consultant Pharmacy Services. (2016) A guide to deprescribing (online). Available from: https:// www.consultantpharmacyservices.com.au/uploads/Documents/ Deprescribing\%202016\%20 Version/ 00\%20General\%20Fact\%20Sheet\%20(SINGLE).pdf

Cumbria, N. H. S. (2013). STOPP/START toolkit supporting Medication Review. Medicines Management Team, February.

Department of Health and Social Care (2018) Matt Hancock orders review into overprescribing in the NHS (online). Available from: https://www.gov.uk/government/news/matt-hancockorders-review-into-over-prescribing-in-the-nhs

Describing deprescribing (2014) Drug and Therapeutics Bulletin, 52(3). https://dtb.bmj.com/content/52/3/25

Duerden, M., Avery, T., \& Payne, R. (2013) Polypharmacy and medicines optimisation: Making it safe and sound (online). Available from: https://www.kingsfund.org.uk/publications/ polypharmacy-and-medicines-optimisation 
Fick, D. M., Semla, T. P., \& Beizer, J. (2015). American Geriatrics Society 2015 Beers Criteria Update Expert Panel. American Geriatrics Society 2015 updated beers criteria for potentially inappropriate medication use in older adults. Journal of American Geriatric Society, 63(11), 2227-2246.

Fulford, K.W. (2011) Bringing together values-based and evidence-based medicine: UK Department of Health Initiatives in the 'Personalization' of Care. Journal of evaluation in clinical practice. Journal of Evaluation in Clinical Practice, 17(2), 341-3. https://doi.org/10.1111/i.1365-2753.2010.01578.x

General Pharmaceutical Council (2020). Accredited MPharm degrees (online). Available from: https://www.pharmacyregulation.org/ education/approved-providers-education-and-training/accreditedmpharm-degrees

Gowan, J. (2018) Deprescribing Medicines (CPD course) (online). Available from: https://www.ausmed.co.uk/cpd/courses/ deprescribing-medicines

Jubraj, B., Marvin, V., Poots, AJ., Patel, S., Bovill, I., Barnett, N., Issen, L., Bell, D. (2015) A pilot survey of junior doctors' attitudes and awareness around medication review: time to change our educational approach? European Journal of Hospital Pharmacy, 22(4) 243-248. https://doi.org/10.1136/ejhpharm-2015-000664

Institute for Healthcare Improvement. Ask Me 3: Good Questions for Your Good Health (online). Available from:

http://www.ihi.org/resources/Pages/Tools/Ask-Me-3-GoodQuestions-for-Your-Good-Health.aspx

Lewis, T.L. (2005). Medication review for the 10-minute consultation: The NO TEARS Tool. Geriatric Aging, 8(6), 43-45.

National Institute for Health and Care Excellence.(2015) Medicines optimisation: the safe and effective use of medicines to enable the best possible outcomes (online). Available from: https://www.nice.org.uk/guidance/ng5/chapter/1Recommendations\#medication-review

National Institute for Health and Care Excellence. (2016) Multimorbidity: clinical assessment and management(online). Avialable from: https://www.nice.org.uk/guidance/ng56

NHS England (2019). The NHS Long Term Plan (online). Available from: https://www.longtermplan.nhs.uk/wp-content/uploads/ 2019/08/nhs-long-term-plan-version-1.2.pdf

NHS Scotland and the Scottish Government (2018). Polypharmacy guidance realistic prescribing $3^{\text {rd }}$ Edition (online). Available from: https://www.therapeutics.scot.nhs.uk/wpcontent/uploads/2018/04/Polypharmacy-Guidance-2018.pdf

NICE (National Institute for Health and Care Excellence). (2016)

Multimorbidity: clinical assessment and management. NICE guideline [NG56].

O'Mahony, D., O'Sullivan, D., Byrne, S., O'Connor, M.N., Ryan, C., \& Gallagher, P. (2015). STOPP/START criteria for potentially inappropriate prescribing in older people: version 2. Age and Ageing, 44(2), 213-218. https://doi.org/10.1093/ageing/afx178
Poots, A.J., Jubraj, B., \& Barnett, N.L.. (2017) Education around deprescribing: 'spread and embed' the story so far. European Journal of Hospital Pharmacy, 24(1), 7-9.

Royal Pharmaceutical Society. (2014) New app to assist RPS members (online). Available from: https://pharmaceuticaljournal.com/article/feature/new-app-to-assist-rps-members

Royal Pharmaceutical Society. Making the most of your medicines (online). Available from: https://www.rpharms.com/ Portals/O/RPS\%20document\%20library/Open\%20access/Hub/ Medicines\%20optimisation/patients---making-the-most-ofmedicines.pdf

Reeve, E., Low, L.F., Hilmer, S.N. (2016) Beliefs and attitudes of older adults and carers about deprescribing of medications: a qualitative focus group study. The British journal of general practice: the journal of the Royal College of General Practitioners, 66(649). https://doi.org/10.3399/bjgp16X685669

Sackett, D.L., Rosenberg, W.M.C., Muir Gray, J.A., Haynes, R.B., \& Richardson, W.S. (1996) Evidence based medicine: what it is and what it isn't. British Medical Journal, 312, 71-72. https://doi.org/ $\underline{10.1136 / \mathrm{bmj} .312 .7023 .71}$

Saheb, M.A., Jubraj, B., Bovill, I., Kuo, S., \& Marvin, V. (2014) Intermediate Care: An optimal setting for review of inappropriate medication in elderly patients. Geriatric Medicine. 13-17

Scott, I.A., Hilmer, S.N., Reeve, E., Potter, K., Le Couteur, D., Rigby, D., Gnjidic, D., Del Mar, C.B., Roughead, E.E., Page, A., Jansen, J., \& Martin, J.H. (2015). Reducing inappropriate polypharmacy: the process of deprescribing. JAMA internal medicine, 175(5), 827834. https://doi.org/10.1001/jamainternmed.2015.0324

Scottish Government Polypharmacy Model of Care Group. Polypharmacy guidance, realistic prescribing. 3rd edn. Edinburgh: Scottish Government, 2018. Available from: https:// www.therapeutics.scot.nhs.uk/wp-content/uploads/2018/09/ Polypharmacy-Guidance-2018.pdf

Stevenson, J. M., Williams, J. L., Burnham, T. G., Prevost, A. T., Schiff, R., Erskine, S. D., \& Davies, J. G. (2014). Predicting adverse drug reactions in older adults; a systematic review of the risk prediction models. Clinical interventions in aging, 9, 1581-1593. https://doi.org/10.2147/CIA.S65475

Tinetti, M.E., Bogardus, S.T., Agostini, J.V. (2004) Potential Pitfalls of Disease-Specific Guidelines for Patients with Multiple Conditions. The New England journal of medicine, 351(27), 2870-2874. https://doi.org/10.1056/NEJMsb042458

World Health Organisation. (2017) The third WHO Global Patient Safety Challenge: Medication Without Harm. Available from: https://apps.who.int/iris/handle/10665/255263 


\section{Appendix}

Appendix 1: Proforma - deprescribing and polypharmacy teaching

Review of polypharmacy and deprescribing teaching: ANALYSIS PROFORMA

1.Background / demographic detail.

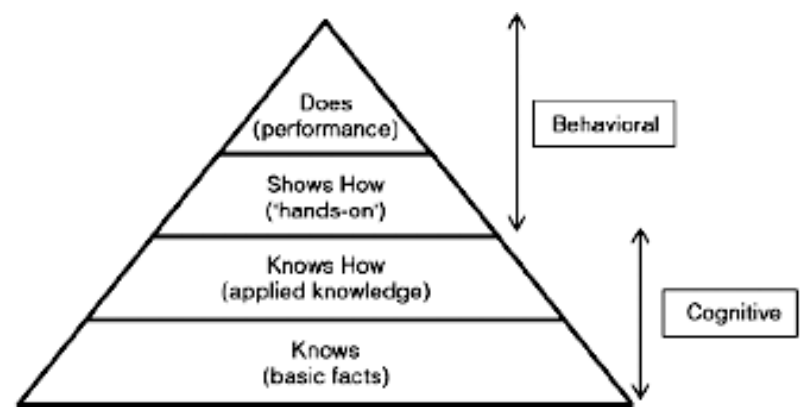

2.Which of the following topics are covered? (please circle)

Polypharmacy Medication review Deprescribing

Which patient groups or conditions are covered with respect to these topics

3. Are any particular tools, e.g. medication review tools such as STOPP/ START/Beers/STOPIT cited

4. In which of the following topic areas are learning outcomes defined? (please circle)

Polypharmacy Medication review Deprescribing

5. Please circle the level in Miller's pyramid below that the teaching aims to deliver

a. E.g. basic introduction vs ask the students to apply in cases

6. Are any gaps acknowledged (e.g. we don't cover but we should)? $Y / N$

If yes: state the key words or short phrases:

7. Are any intentions stated (e.g. to introduce teaching, to develop it further)? $\mathrm{Y} / \mathrm{N}$

If yes: state the key words or short phrases: 